\title{
LOST IN TRANSITION? EMPLOYMENT AND FAMILY CHANGE FOR MID-LIFE MEN
}

\author{
Paul Callister and David Rea \\ Institute of Policy Studies \\ Victoria University of Wellington
}

\begin{abstract}
Under the provocative title 'Useless, jobless men - the social blight of our age'?, a May 2010 British newspaper article posed the question as to whether the UK benefits system has produced an 'emasculated' generation of men who can find neither work nor a wife. Informed by a review of international literature, we use census, HLFS and benefit data to explore these issues within a New Zealand context. We demonstrate how a group of mid life males on the margins of work and family life have emerged in New Zealand and show how this has been driven by a number of changes in labour markets, particularly in relation to the low skilled; in marriage markets; and through the workings of the benefit system. Although our research suggests that the size of this marginalised group is relatively small, the men we are concerned about are at the heart of a number of difficult contemporary policy issues such as the rise in disability benefit receipt and incarceration. Historically, low skilled males were a major focus of policy - the breadwinner model - which focussed on reinforcing the social expectation that men's role was in work and married. We suggest there now needs to be a renewed policy focus on this group. However rather than attempting to return the world to the 1950s, the task for policy makers is to consider how best to create policy settings that are effective for the contemporary structure of work and family life.
\end{abstract}

\section{Introduction}

In a July 2010 edition of Newsweek magazine headlines stated Women will rule the world: Men were the main victims of the recession. The recovery will be female (Singh, 2010). Under an equally provocative title Useless, jobless men - the social blight of our age? a May 2010 British newspaper article had posed the question as to whether the UK benefits system had produced an 'emasculated' generation of men who can find neither work nor a wife (Cavendish, 2010). While the idea of women ruling the world might be new, suggestions that jobless men are 'useless', and perhaps even viewed a threat to society, are of course not new themes. While a work of fiction, John Steinbeck's 1930s book The Grapes of Wrath (1939) clearly describes how unemployed US men in the Great Depression felt inadequate when unable to provide for their families and were often perceived as a threat in local communities. Over 70 years later, another US novel, Philipp Meyer's 2009 American Rust, sets out similar themes.

But it is not only fiction writers who consider these ideas. In the mid 1990s, when there was increasing concern being expressed about male unemployment in many industrialised countries, the Economist (1996: 27) noted:

Consider for a moment a neighbourhood in which most working-age women are not in paid jobs. This may conjure up a picture of tidy homes, children at play and gossip. Now think of a neighbourhood in which most men are jobless. The picture is more sinister. Areas of male idleness are considered, and often are, places of deterioration, disorder and danger. Non-working women are mothers; non-working men, a blight.
A decade and a half later in the midst of the US recession Peck (2010) was equally gloomy.

\begin{abstract}
The Great Recession may be over, but this era of high joblessness is probably just beginning. Before it ends, it will likely change the life course and character of a generation of young adults. It will leave an indelible imprint on many blue-collar men. It could cripple marriage as an institution in many communities. It may already be plunging many inner cities into a despair not seen for decades. Ultimately, it is likely to warp our politics, our culture, and the character of our society for years to come.
\end{abstract}

In the past, recessions or full depressions were seen as being part of an economic cycle. Men might be out of work in large numbers but eventually the economy would pick up and prime working aged men would be back in paid work and supporting families. Certainly, in New Zealand in the 1950 s and 1960 s most mid-life men were employed full time, were married and were raising children. But in the 2010 Newsweek article, Larry Summers, then economic adviser to the US President, is quoted as saying "when the economy recovers, five years from now, one in six men who are 25 to 54 will not be working" (Singh, 2010). If Summers or Peck are correct, this suggests there has been a major structural shift in industrialised economies. And given a host of evidence that links employment outcomes to partnering, it also suggests traditional roles for a group of males in relation to families will continue to be challenged. 
Informed by a review of international literature (Callister and Rea, 2010), we draw on census, HLFS and benefit data to demonstrate how a group of mid life males on the margins of work and family life have emerged in New Zealand and show how this has been driven by a number of changes in labour markets, particularly in relation to the low skilled; in marriage markets; and through the workings of the benefit system. The 2006 census data possibly present an overly optimistic picture given that this was a time of very strong labour markets. But it the only relatively reliable source of data on partnering patterns.

Although our research suggests that the size of this marginalised group is relatively small, the men we are concerned about are at the heart of a number of difficult contemporary policy issues such as the rise in disability benefit receipt and incarceration. Historically, low skilled males were a major focus of policy - the breadwinner model - which focussed on reinforcing the social expectation that men's role was in work and married. We suggest there now needs to be a renewed policy focus on this group. However rather than attempting to return the world to the 1950s, the task for policy makers is to consider how best to create policy settings that are effective for the contemporary structure of work and family life.

\section{Broad changes in paid work}

As a broad starting point using New Zealand data figure 1 shows employment rates for men and women from 1956 through to late 2010 .

\section{Figure 1}

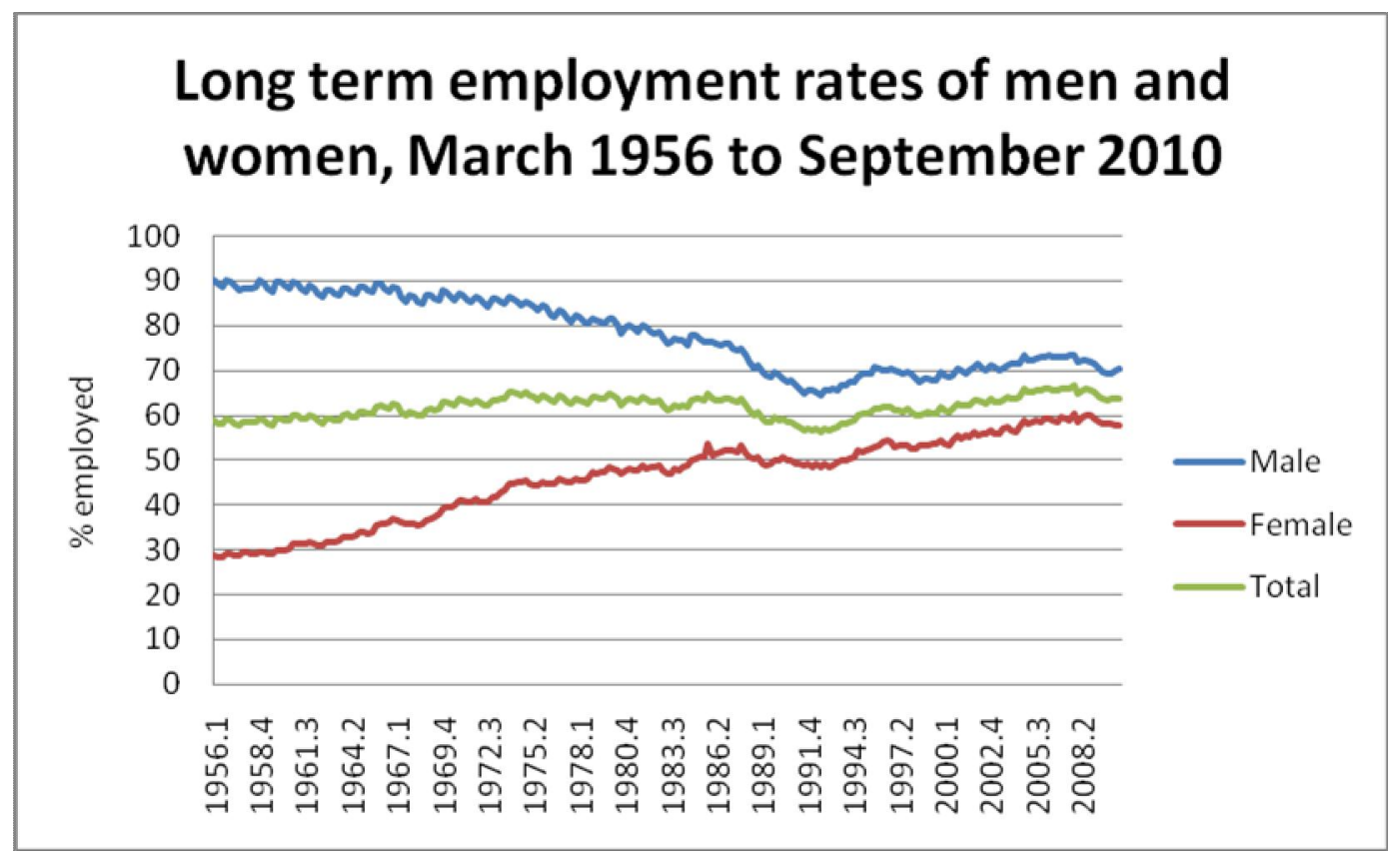

Source: Chapple 1994, HLFS 
Underlying figure 1 are a complex set of changes in employment in different age groups, some shifts in gender roles within households and underlying changes in the industries and occupations. But in this figure the effect of recessions is clear, affecting both male and female employment levels. This data indicate relatively high, but declining employment of males in the 1970s, and a low point in employment in the early 1990s. The data also show the downturn in employment of both men and women in the latest recession with, in fact, the September quarter showing higher unemployment rates for women than men.

From the time the LEW conferences began, papers have tracked employment over periods of growth and periods of decline. A number of long term trends are clear.

- Managerial, professional and service worker occupations provide an increasing proportion of jobs

- While many of these jobs are high skill a number of lower skill occupations continue to grow

- There has been some overall shift from jobs that could be considered manual to those seen as non-manual

- The occupations declining over the long term included traditionally male ones of agriculture and fisheries workers as well as trades workers.

- Some industries are particularly prone to 'booms and busts', one being the building industry

Due primarily to women being increasingly better educated than men, women have been moving into managerial and professional occupations although are still under-represented at the senior level of these professions (McGregor, 2010). For a variety of reasons are over-represented in many services sectors jobs, particularly those delivering 'in person services". In addition, women began from a lower base of employment and so had more potential for strong supply side responses to any growth in employment. It is therefore not surprising that in simple numbers of jobs the changes in recent decades have favoured women. While there were major fluctuations within the time period, census data show that over the time 1981 to 2006 the overall number of people employed lifted quite strongly. Between 1981 and 2006 there was a $48.1 \%$ increase in the employed population. This increase was weighted towards women, with a lift of $84.2 \%$ in the number of employed women but an increase of only $26.1 \%$ in the number of employed men (Newell, 2009). As a result, the ratio of working men to women changed greatly between 1981 and 2006. In 1981, there were 1.6 working men for every working woman, but by 2006 this had converged to only 1.1 (ibid).

Switching to HLFS data, but keeping the March quarter to allow some compatibility with the census, if March 2006 is compared with March 2010 , then over this recent period of initial strong job growth then recent decline we see that there was an addition of 17,400 jobs held by men, 32,500 by women, with a total gain of just under 50,000 jobs. Figure 2 shows the change in jobs by main industry sector from March 2006 to March 2010. While there were a range of industries where male jobs increased, the two standout industries are education and training and health care and social assistance, both strongly female sectors. In discussing income rather than employment growth, Coleman and McDonald (2010) point out that government funding has very much underpinned growth in these areas. This in itself created some vulnerability to this growth. If government spending is severely constrained, as it is in late 2010 , then restructuring of the state sector could see women losing their jobs faster than men. In addition, changes such as a low exchange rate with Australia can see exports boosted with more jobs created in manufacturing and gains for males. But long term demographic and technological change suggest that there will be continuing pressure on male dominated areas such as manufacturing and growth in female areas such as health care. 
Figure 2: Change in number of male and female jobs in each main industry group, March 2006 to March 2010

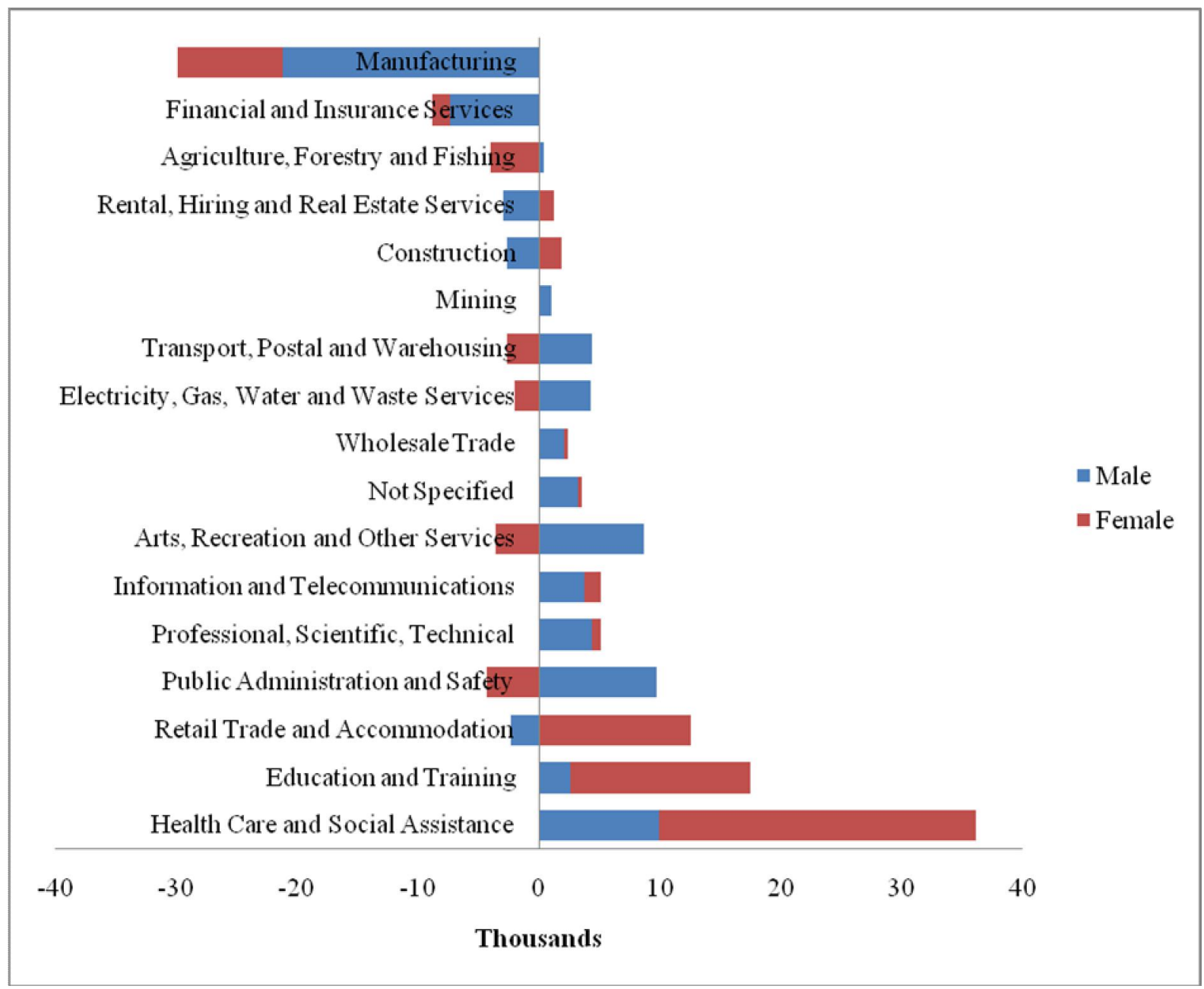

Source: HLFS

In the US, broad patterns of unequal gains and losses of jobs by women and men have led to what some have termed a 'Mancession'. Drawing on July 2010 seasonally adjusted data there were 8.5 million men and nearly 6.1 million women aged 16 and over who were recorded as unemployed in the US. ${ }^{1}$ This was an unemployment rate of $10.4 \%$ for men and $8.5 \%$ for women. In New Zealand, the seasonally adjusted September quarter data showed there were 71,000 men and 80,000 women recorded as unemployed. The September quarter data challenge the idea of a 'Mancession' taking place in New Zealand (Table 1).

Table 1: Seasonally adjusted unemployment rate, New Zealand

\begin{tabular}{llrr}
\hline & & Male & Female \\
\hline $\mathbf{2 0 0 8}$ & Jun & 4.0 & 3.9 \\
& Sep & 4.3 & 4.2 \\
& Dec & 4.6 & 4.6 \\
$\mathbf{2 0 0 9}$ & Mar & 5.2 & 5.0 \\
& Jun & 5.7 & 6.2 \\
& Sep & 6.5 & 6.5 \\
& Dec & 7.2 & 7.0 \\
$\mathbf{2 0 1 0}$ & Mar & 5.8 & 6.4 \\
& Jun & 6.9 & 6.8 \\
\hline
\end{tabular}




\begin{tabular}{lll} 
Sep & 5.7 & 7.2 \\
\hline
\end{tabular}

Source: HLFS

To better understand structural shifts that have been affecting New Zealand males, there is a need to delve below the broad measures and track changes within age and education groups. This includes tracking both employment and living arrangement.

\section{Trends in employment for mid-life men}

Considering employment on its own, from the mid 1970s labour force participation rates (the employed plus the unemployed seeking work) began to decline. In 1976, almost $99 \%$ of men aged 30-44 were participating in the labour markets, but by 2006 only $90 \%$ of men in the age group were participating in the labour force. This represents a nine percentage point decline in the proportion of mid life men in the labour force. But the changes have been more dramatic for the low skilled. In the March 2010 quarter, the Household Labour Force Survey showed that the employment rate for those with post school qualifications in this age group was $92 \% \%$ but for those with no formal qualifications it was just over $73 \%$.Yet back in 1986, employment rates for men in this age group with no qualifications was just over $90 \%$. A number of Australian and New Zealand studies indicate that the low skilled are particularly at risk of being completely outside of the labour market, that is no longer actively seeking paid work.

\section{Trends in living arrangement for mid- life men}

Partnering rates have also been declining. As recent as 1986 , over $80 \%$ of males in the $30-44$ age group who lived in private dwellings were partnered. But by 2006 this had declined to under $70 \%$. Again, in both New Zealand and Australia it is the poorly educated who are less likely to be partnered. In $1986,80 \%$ of those with no qualifications in this age group were partnered, but by 2006 this was down to $61 \%$. For those with post school qualifications partnering rates were still just under $80 \%$ in 2006 .

\section{Trends in employment and living arrangement for mid-life men}

Linked to fewer mid life men living in couples, a smaller proportion also now live with dependent children. Bringing the three variables together, we can attempt to calculate the proportion of mid life men who are not employed, not living in a couple and not living with a dependent child (Table 2). In doing so we have to limit our calculations to those living in private dwellings. In 2006, over 14,000 men aged $30-44$, or about $4 \%$ of this age group, lived in non-private dwellings in New Zealand. Given that non-private dwellings include psychiatric hospitals, night shelters and prisons, the exclusion of men in these settings in our calculations is likely to lead to an underestimation of those on the margins. The 2006 census shows that men disconnected in this way from both employment and family represent just $4 \%$ of men in this mid life age group at this point in time. Yet, this still represents over 16,000 New Zealand men living in private dwellings in this age group in 2006. For a variety of reasons, including the non completion of census forms, we think the actual numbers will be somewhat higher. Given recent trends in HLFS data, we suggest that this proportion would have also risen above $4 \%$ by mid 2010. 
Table 2: Employment, partnering and living with dependent children, males aged 30-44 living in private dwellings, 1986-2006

\begin{tabular}{|c|c|c|c|c|c|c|c|c|c|}
\hline & 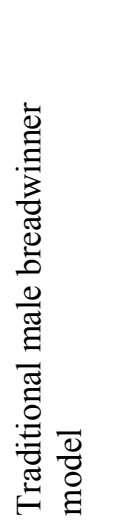 & 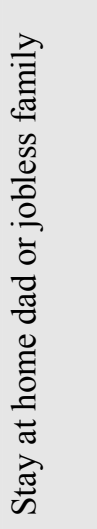 & 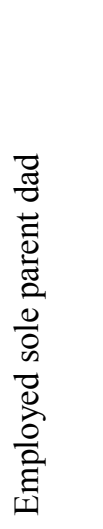 & 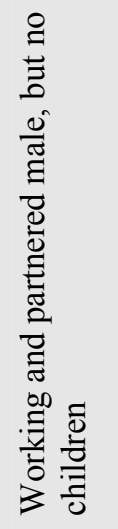 & 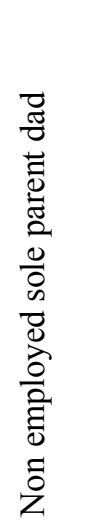 & 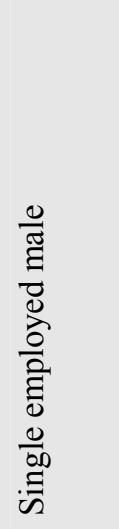 & 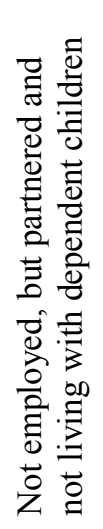 & 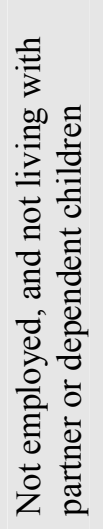 & 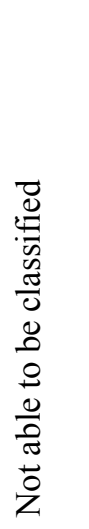 \\
\hline 1986 & 64.6 & 1.9 & 2.6 & 11.7 & 0.9 & 11.9 & 0.4 & 1.4 & 4.5 \\
\hline 1991 & 53.6 & 6.2 & 1.8 & 12.7 & 1.4 & 13.9 & 1.3 & 5.0 & 4.0 \\
\hline 1996 & 48.8 & 5.7 & 1.6 & 15.9 & 1.2 & 13.6 & 2.0 & 4.2 & 7.1 \\
\hline 2001 & 46.3 & 4.7 & 3.7 & 14.3 & 2.0 & 15.5 & 1.3 & 4.6 & 7.6 \\
\hline 2006 & 47.2 & 3.8 & 4.0 & 15.8 & 1.7 & 15.8 & 1.2 & 4.0 & 6.5 \\
\hline
\end{tabular}

Source: Census of Population and Dwellings, Statistics New Zealand

The relations between education, employment status, and living arrangement and for males are of course complex. And certainly not all the changes are bad. There has been an expansion of the possible work and living arrangements open to males. For example gay men no longer need to try and mould themselves into traditional marriages, some fathers can choose to be 'househusbands' or undertake study while their partner supports them and couples can voluntarily decide to be 'childfree'.

However, overall the group who tend to have little formal education are the ones then over-represented in terms of being on the margins of employment and family life. Maori and Pacific men are overrepresented amongst those with poor outcomes in all these areas.

\section{Why are a group of mid life men excluded from work and family life?}

Assessing the cause of social change is always a complicated business. But evidence from national and international research point to a range of factors have contributed to the increasing prevalence of men outside the labour market and families (Callister and Rea, 2010). Our overall summary of what has occurred is that:
- historically social norms, public policy and economic growth lent some support to the male breadwinner model

- but there were long term social changes to partnering arrangements and the employment of women that began to undermine the model

- and also by the 1970 s protection of male employment had become increasingly expensive, partly because of competition from emerging economies

- both economic reform and longer term underlying changes in the structure of the economy led to wide ranging job losses particularly amongst men in agriculture and manufacturing - and in the subsequent period unskilled men were at the bottom of the queue for jobs

- the liberalised economy had fewer unskilled jobs, but there was also some competition from women, and possibly some competition from older workers

- some unskilled men ended up on an unemployment benefit during the recession of the 1990s- and drifted onto Sickness Benefits and Invalid Benefits - possibly because unemployment made them sick (Blakely, 2010) - but also because of pre existing low 
level conditions which in the past had not been an impediment to employment

- at the same time unemployment and longer term withdrawal from the labour market made some men less attractive as partners

- women had greater opportunities to support themselves, and potentially children, on their own through better earning opportunities for one group and great state income and service support for another group

- the absence of being partnered, and also being employed, deprived a group of men of important social support and constraints. It is likely that the absence of these protective factors has further entrenched the exclusion of this group of males.

- particular policies, notably imprisonment reinforces some of these trends

Although the size of the group is relatively small, the men we are concerned about are at the heart of a number of difficult contemporary policy issues such as the rise in disability benefit receipt and incarceration. This is because there are wide ranging individual and social consequences to men not participating in employment or family life. These include:

- long term joblessness and low income

- poor health - depression, alcohol and drug dependence, and suicide

- loneliness

- homelessness

- $\quad$ sometimes adverse effects on children

- crime

- increased expenditure on Sickness Benefit/Invalid Benefit as well as the Domestic Purposes Benefit

The small, but nevertheless growing, numbers of 'marginal men' have economic, fiscal and social consequences. These include

- $\quad$ lost economic output

- costs of benefit receipt amongst men as well as families

- other adverse social and economic consequences such as criminal offending.

\section{Policy implications}

Historically, low skilled males were a major focus of policy - the breadwinner model - which focussed on reinforcing the social expectation that men's role was in work and married. There now needs to be a renewed focus on males. However rather than attempting to return the world to the 1950 s, the task for policy makers is to consider how best to create policy settings that are effective for the contemporary structure of work and family life. In doing so we also need to understand the heterogeneity of the population and in particular need to come to grips with the different choices that men might be making. At one end of the spectrum there are those men where the options of employment and family life are simply not available, while for others not being employed or living with family is a way of avoiding responsibilities.

There are a number of policy areas where more attention needs to be given to men, including education, family and criminal law, wider family policy, labour markets and, potentially, health policy. In terms of health policy, Australia and New Zealand are currently taking different approaches. In May 2010, the Australian government released its first National Male Health Policy but in New Zealand there is on-going debate about the strengths and weaknesses of developing gender specific health policy. ${ }^{2}$

Many of these policy issues cannot be seen in isolation. In the US, as part of welfare reform there have been some attempts to strengthen relationships for fragile opposite sex families. One extreme of this is to promote the institution of marriage. But government and non-government agencies have focussed more on helping fathers become more engaged with their children, whether it is spending more time caring for them or simply paying income support when separated. For example, the US Department of Health \& Human Services hosts a website entitled Promoting Responsible Fatherhood. ${ }^{3}$ In these activities, there has been a special focus on the African American population, with its high sole parenthood, high unemployment of males and, connected with this, high rates of incarceration. But long time commentator on the plight of black males and their families, William Julius Wilson (2009), makes the point that creating well paid jobs for these men is fundamental for supporting families and children.

...take the problem of black male fatherhood. I would argue that programs focusing on the cultural problems pertaining to fatherhood, including attitudes concerning paternity, without confronting the broader and more fundamental issues of restricted economic opportunities have limited chances to succeed. In my view the most effective fatherhood programs in the inner city will be those that address the framing of attitudes, norms, and behaviors in combination with local and national attempts to improve job prospects. Only when black fathers have a realistic 
opportunity to adequately care for their children financially will they be able to envision a more family centered life for themselves and their children.

As papers presented at previous LEW conferences show, there is no simple policy fix. What is needed is innovative thinking in areas of policy making. As part of the process of exploring policy options there is also a need to think about the institutions that focus especially on gender dimensions of policy. In 1967 the National Advisory Council for the Employment of Women was set up. An organisation that still operates, its role has been undertaking research and disseminating information with regards to women's position in education, the workplace and in the home and advising the Minister of Labour. In 1984, a Labour Cabinet approved the establishment of the Ministry of Women's Affairs as a separate department of state to advise government of the differential impact of policies on women, to initiate and support legislation to promote equality for women and to nominate suitable women for appointment to statutory bodies. The Ministry of Women's Affairs was officially opened in 1986 and continues to operate.

These types of institution help frame debates. In contrast to the New Zealand institutions that focus primarily on women, in some nations alternative institutions have now been set up to undertake gender analysis and these come from the idea that both men and women can, in particular circumstances, be disadvantaged. Not surprising some of the more innovative examples come from countries which have concerns about multiple dimensions of inequality. For instance in Finland gender equality issues fall within the scope of the Ministry of Social Affairs. Those responsible for the practical implementation of equality are the Ombudsman for Equality, the Gender Equality Unit, and the Council for Equality. In another Nordic country Sweden gender analysis is undertaken within a wider Ministry of Integration and Gender Equality. While many of the activities undertaken in the area of gender analysis are similar to those carried out in New Zealand's MWA, others would fall outside of its interests, for example considering relative male disadvantage in education.

\section{Future research}

The end point for much of the analysis in this paper was the 2006 census, a high point in employment. The 2011 census is likely to be undertaken at a time of lower employment so tracking how work and family patterns continue to evolve will be useful. However a range of other data sources could be used to better understand the changing patterns of work for mid-life males, especially the low skilled. In particular, through the use of administrative data, the ability to now track students from school into tertiary training, employment or onto a benefit will help us better understand the links between education (or the lack of it) and success in the labour market. Using longitudinal data sources will also help us better understand the dynamics of family formation and dissolution and how this might relate to labour market change. Finally, gaining a better understanding of the role of Australia as a 'pressure cooker valve', that potentially has absorbed some of our lower skilled workers, will be useful.

\section{Notes}

1. http://www.bls.gov/news.release/empsit.t1 $0 . \mathrm{htm}$

2. See http://ips.ac.nz/events/completedactivities/Missing\%20men/Missing\%20M en $\% 20$ Workshops.html

3. http://fatherhood.hhs.gov/

\section{References}

Blakely, T. (2010). Unemployment and mortality: Learning from the past in times of resurging unemployment. Journal of Epidemiological Community Health 64(1), 3-4.

Callister, P. and Rea, D. (2010). Why are a group of mid-life men on the margins of work and family? A literature review, IPS Working Paper 10/13, Wellington: Institute of Policy Studies.

Cavendish, C. (2010). Useless, jobless men - the social blight of our age: The benefits system has produced an emasculated generation who can find neither work nor a wife, Times Online, May 28, http://www.timesonline.co.uk/tol/comment/ columnists/camilla_cavendish/article713852 0. ece

Coleman, A and McDonald, H. (2010). No Country for Old Men: A Note on the TransTasman Income Divide, LEW PAPER IN THIS VOL

McGregor, J. (2010). New Zealand Census of Women's Participation 2010, Wellington: Human Rights Commission, http://www.hrc.co.nz/hrc new/hrc/cms/files/ documents/05-Nov-2010 09-2940_HRC_Womens_Census_2010_WEB.pdf 
Newell, J. (2009). A Comparison of New Zealand and Australian Labour Markets: Current similarities and long term trends, working paper 09/02. Wellington: Monitoring and Evaluation Research Associates.

Peck, D. (2010). How a new jobless era will transform America, The Atlantic, March. www.theatlantic.com/magazine/archive/201 0/03/how-a-new-jobless-era-will-transformamerica/7919.
Singh, R. (2010). Women will rule the world: Men were the main victims of the recession. The recovery will be female, Newsweek, July 6, http://www.newsweek.com/2010/07/06/wo men-will-rule-the-world.html

The Economist (1996). September 28, 27

Wilson, W. J. (2009). Toward a framework for understanding forces that contribute to or reinforce racial inequality. Race and Social Problems 1, 3-11. 